\title{
The efficacy of Herceptin therapies is influenced by the expression of other erbB receptors, their ligands and the activation of downstream signalling proteins
}

\author{
BL Smith', D Chin², W Maltzman², K Crosby', GN Hortobagyi ${ }^{3}$ and SS Bacus ${ }^{*, 2}$ \\ 'Cell Signaling Technology, I66B Cummings Center, Beverly, MA 01915, USA; ${ }^{2}$ Targeted Molecular Diagnostics, Inc., 610 Oakmont Lane, Westmont, \\ IL 6055, USA; ${ }^{3}$ University of Texas MD Anderson Cancer Center, 1515 Holcombe Blvd, Unit 424, Houston, TX 77030, USA
}

ErbB2 and EGFR are attractive oncology therapeutic targets as their overexpression in tumors predicts a poorer clinical outcome in a variety of epithelial malignancies. However, clinical results with therapeutic compounds targeting these receptors have been mixed. Therefore, there is a need for improved predictive biomarkers for these targeted therapeutics. In this study we analysed tissue microarrays of patients treated with combination chemotherapy and Herceptin for expression or phosphorylation of signalling proteins associated with erbB receptors to identify protein biomarkers that are predictive of breast cancer patient response. A comparison of expression or phosphorylation of these markers with patient outcome revealed that response to Herceptin depended not only on expression levels of erbB2 but also on expression of EGFR, expression of erbB ligands, expression of other receptors and phosphorylation of downstream proteins. Elucidating the biological effects of EGFR/erbB2 targeted therapeutics will enable patient tumor profiling to identify likely responders and the determination of biologically effective doses that allows chronic administration of these agents in order to maximise efficacy.

British Journal of Cancer (2004) 91, I 190- I 194. doi:I 0.1038/sj.bjc.6602090 www.bjcancer.com

Published online 10 August 2004

(c) 2004 Cancer Research UK

Keywords: biomarkers; breast cancer; Herceptin

The erbB family of receptors, namely EGFR and ErbB2, are important drug targets for cancer therapeutics and are the focus of a large number of current clinical trials. In addition, one of the first approved targeted cancer therapeutics was Herceptin, an antibody inhibitor of ErbB2. The successful clinical development of Herceptin depended upon the selection of patients based upon the overexpression of ErbB2. However, the response rate for Herceptin in breast cancer, when used in combination with chemotherapy, was approximately $50 \%$ in the pivotal clinical trial (Hortobagyi, 2001). Importantly, this response rate is observed in patients that are overexpressing ErbB2. Based upon these response rates, it is clear that better predictive markers are needed to select patients for treatment with Herceptin or other erbB inhibitors.

The response rate observed with erbB inhibitors in patients selected solely on the basis of the overexpression of a single erbB receptor is not unexpected given the complexity of erbB signalling. Most tumors of epithelial origin express multiple erbB (HER) receptors and co-express one or more EGF-related ligands, suggesting that autocrine receptor activation plays a role in tumor cellular proliferation. As these ligands activate different erbB receptors, it is possible that multiple erbB receptor combinations might be active in a tumor, a characteristic that could influence its response to an erbB-targeted therapeutic (Karunagaran et al,

*Correspondence: SS Bacus; Email: sbacus@tmdlab.com

Received 29 December 2003; revised 28 June 2004; accepted 29 June 2004; published online 10 August 2004
1996). The ligands present may select the dimerization partners, and may also influence the time course of membrane translocation, activation and internalization of the receptor (Peles et al, 1993; Tzahar et al, 1994; Pinkas-Kramarski et al, 1996). Downstream signalling may be determined by the set of docking proteins that may bind to the activated receptors. For example, erbB3 contains six major docking sites for phosphoinositide-3-kinase (PI3K). NDF/Heregulin ligand stimulation of erbB receptors causes activation of the PI3K pathway and phosphorylation of AKT (Altiok et al, 1999; Liu et al, 1999; Xing et al, 2000). These observations implicate PI3K/AKT in the signalling cascade that results from erbB3 heterodimerisation with overexpressed ErbB2 in breast cancer cells. Importantly, activation of PI3K/AKT promotes cell survival and enhanced tumor aggressiveness (Bacus et al, 2002) and inhibition of the AKT pathway may be required for Herceptin effect (Yakes et al, 2002). Recent results have suggested that erbB receptors may be transactivated by other receptor classes such as $G$ protein coupled receptors, cytokine receptors and insulin-like growth factor receptor (IGF-IR) (Gschwind et al, 2001).

To address the need for predictive biomarkers for Herceptin response in breast cancer patients, we analysed breast cancer tissue sections taken from patients treated with Herceptin and chemotherapy by immunohistochemistry (IHC) for expression of erbB ligands and receptors and phosphorylation of downstream signalling proteins. For this analysis we used tissue microarrays of the samples. Tissue microarrays are a well-validated method to rapidly screen multiple tissue samples under uniform staining and 
scoring conditions (Hoos et al, 2001). The results of the analysis identify a set of biomarkers that best predict patient outcome following Herceptin combination therapies. Patient probability of response ranging from 0 to $100 \%$ was observed based upon the expression or phosphorylation of a small set of ligands, receptors and signalling proteins.

\section{MATERIALS AND METHODS}

Tissue micro-arrays of 250 metastatic breast cancer patients who received first-line chemotherapy together with Herceptin were obtained from Clinomics Biosciences (Pittsfield, MA, USA). All of the tissues were obtained under institutional IRB approval. The histology of the tumors varied with infiltrating ductal carcinoma being most common. All patients received radiotherapy postsurgery. The tissue samples in the array were taken before treatment and were all taken from the primary tumor unless otherwise noted. ErbB2 expression had been determined by the Herceptest on the original biopsies for all patients. Patient response was based upon the case histories at last follow-up as decided by the independent investigators for the clinical trials from which the samples were obtained. Patients who were free of disease at the time of examination after therapy were classified as disease free. Patients whose tumors had not progressed at the time of examination were classified as having stable disease. Patients who were disease free or had stable disease were grouped together as nonprogressors. Patients who redeveloped the disease after therapy or whose tumors progressed were classified as progressors.

EGFR and erbB2 immunostaining was performed by using the prediluted EGFR and erbB2 antibodies from Ventana Medical Instruments, Inc. (VMSI, Tucson, AZ, USA). erbB3 $(1: 10)$ and Heregulin $(1: 25)$ antibodies were obtained from NeoMarkers (Fremont, CA, USA). TGF- $\alpha$ and IGF-IR antibodies were obtained from Oncogene Sciences (San Diego, CA, USA) and NeoMarkers (Fremont, CA, USA), respectively. EGFR, ErbB2, erbB3, IGF-IR, Heregulin and TGF- $\alpha$ were immunostained using the 'BenchMark' (VMSI) with I-VIEW (VMSI) detection chemistry. Phosphospecific HER2 (p-HER2, Y1248), phospho-specific ERK (p-ERK), phospho-AKT (p-AKT) and phospho-S6 ribosomal protein (p-S6) antibodies were obtained from Cell Signalling Technology (Beverly, MA, USA), and immunostained using a labelled streptavidin peroxidase technique. Slides for $\mathrm{p}-\mathrm{S} 6$ ribosomal protein, p-ERK and p-AKT were processed with antigen retrieval using $0.1 \mathrm{M}$ citrate buffer, $\mathrm{pH} 6.0$ in the 'decloaker' (Biocare Corp.) and the sections incubated overnight with the primary antibodies at $4{ }^{\circ} \mathrm{C}$. The next day, the slides were placed onto the Autostainer (Dako Corp.) and the 'LSAB2 kit (Dako) was used as the detection chemistry. DAB (Dako) was used as the chromagen. Slides for p-HER2 were processed with antigen retrieval using $1 \mathrm{mM}$ EDTA, pH 8.0 solution and processed manually using the Vector Elite detection system. After immunostaining, all slides were counterstained manually with $4 \%$ ethyl green (Sigma). ErbB2, EGFR, erbB3, IGF-IR, TGF- $\alpha$, Heregulin, p-ERK, p-AKT and p-S6 ribosomal protein or phosphorylation levels were quantified using alkaline phosphatase or peroxidase techniques and microscope-based image analysis of immunohistochemical stained slides (Bacus et al, 1997). Quantification was by means of a CAS 200 image analyser, as previously described (Bacus and Ruby, 1993). Slides for p-HER2 were scored manually following the criteria of the Herceptest. For the purpose of the analysis, tumors were classified as negative or positive for all antibodies based upon the level of staining. Statistical analysis was performed to quantify frequencies and calculate Pearson $\chi^{2}$ tests of significance for interactions between variables. Comparisons were performed only on samples for which all relevant data was available.

\section{RESULTS}

\section{Analysis of breast cancer tissue arrays}

From the original tissue array of 250 patients, A total of 75 samples were not used in this analysis for lack of clinical data or because the sections did not contain tumor tissue. Of the remaining 175 patients, 28 samples lacked Herceptest results and were also excluded from further analysis. In total, 70 patients were removed from the analysis because of low ErbB2 expression (see below). Of the remaining 77 patients, 73 were taken from the primary tumor, three from lymph nodes and one from an adrenal metastases. The demographics of these patients are presented in Table 1 . The great majority of patients had infiltrating ductal carcinomas and received anthracycline plus cyclophosphamide. All patients had $4 \mathrm{mg} / \mathrm{kg}$ Herceptin loading dosage and $2 \mathrm{mg} / \mathrm{kg}$ weekly maintenance dosage. Overall, $15 \%$ of the patients were disease free or had stable disease while $85 \%$ had re-occurrence or progression of disease as determined at the last examination.

ErbB2 expression levels were also analysed using the arrays (results not shown) and compared to the reported Herceptest results. Our results obtained with the arrays were very similar to the Herceptest results. Therefore, in this analysis we used the Herceptest results obtained from the original sections. In total, 70 patients had $2+$ or less staining intensity whereas 77 had +3 ErbB2 staining (these patients had been given Herceptin based upon a serum assay for ErbB2 expression). As expected, we observed ErbB2 expression strongly correlated with patient response; $100 \%$ of the 0 or $1+$ ErbB2 patients progressed while only $77 \%$ of the $3+$ patients progressed. This response rate is lower than what has been reported previously (Baselga, 2002). Based upon these results, we concentrated our analysis of biomarkers on patients that expressed erbB2 at the highest or +3 level, as these are the patients most likely to respond to Herceptin.

The 77 patients who overexpressed ErbB2 at the $3+$ level were analysed for expression levels of p-HER2, EGFR, erbB3, IGF-IR, $\mathrm{NDF} /$ Heregulin, and TGF- $\alpha$ as well as activated downstream signals p-ERK and p-AKT (phosphorylated forms of ERK and AKT) and the downstream signal, p-S6 (or phosphorylated S6 ribosomal protein). Representative immunohistochemical results are presented in Figure 1.

Similar to ErbB2, EGFR expression significantly correlated with patient outcome (Table 2). Among these Herceptin-treated patients, the percentage of nonprogressing patients was $30 \%$ for EGFR-positive patients and 9\% for EGFR-negative patients as compared to $23 \%$ for the total group of patients. erbB3 is thought to play an important role in downstream erbB signalling in that is has PI-3-Kinase docking sites and forms active

Table I Demographics of breast cancer patient samples used in final analysis of tissue microarray

\begin{tabular}{lc}
\hline & Number of patients \\
\hline Patients included in final analysis & 77 \\
Pathology & \\
Infiltrating ductal carcinoma & 65 \\
Lobular carcinoma & 3 \\
Medullary carcinoma & 1 \\
Metastatic breast carcinoma & 4 \\
Scirrhous carcinoma & 2 \\
Treatment (plus Herceptin) & \\
Anthracycline plus cyclophosphamide & 63 \\
Doxorubicin & 14
\end{tabular}

Analysis on tissue array samples for which clinical and Herceptest data were available and who overexpressed ErbB2. 


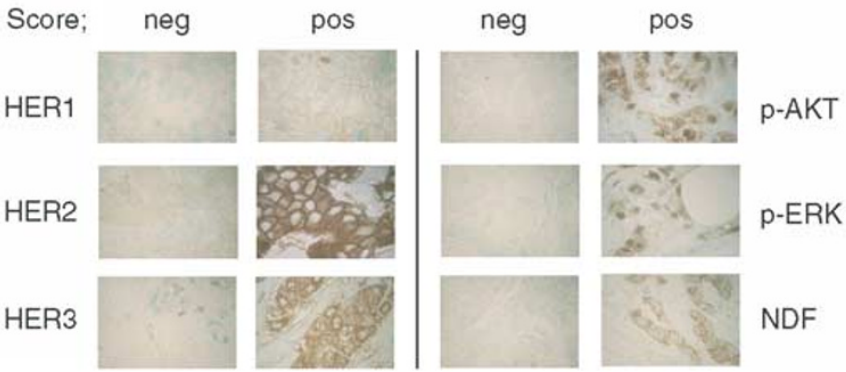

Figure I Representative images of $\mathrm{IHC}$ results obtained from breast cancer patient samples arrayed in a tissue microarray.

Table 2 Receptor tyrosine kinase expression vs patient outcome

\begin{tabular}{|c|c|c|c|c|}
\hline Patient group & $n$ & $\begin{array}{c}\% \\
\text { Nonprogressors }\end{array}$ & $\begin{array}{c}\% \\
\text { Progressors }\end{array}$ & $\begin{array}{l}\chi^{2} \text { value } / \\
P \text {-value }\end{array}$ \\
\hline EGFR positive & 43 & 30 & 70 & $3.97 / 0.05$ \\
\hline EGFR negative & 23 & 9 & 91 & \\
\hline Total & 66 & 23 & 77 & \\
\hline erbB3 positive & 70 & 29 & 71 & $0.62 / \mathrm{NS}$ \\
\hline erbB3 negative & 7 & 43 & 57 & \\
\hline Total & 77 & 30 & 70 & \\
\hline p-erbB2 positive & 17 & 23 & 77 & $0.42 / \mathrm{NS}$ \\
\hline p-erbB2 negative & 60 & 32 & 68 & \\
\hline Total & 77 & 30 & 70 & \\
\hline IGF-IR positive & 33 & 24 & 76 & $1.93 / \mathrm{NS}$ \\
\hline IGF-IR negative & 35 & 40 & 60 & \\
\hline Total & 68 & 32 & 68 & \\
\hline
\end{tabular}

Analysis on tissue array samples for which clinical and Herceptest data were available and who overexpressed ErbB2 at the 3+ level.

heterodimers with the other erbB receptors. Among the 77 patients, 70 of them expressed erbB3. ErbB3 expression did not significantly correlate with patient outcome, p-AKT level or NDF expression although the low number of erbB3 negative patients limits these comparisons in this data set. Interestingly, p-HER 2 was only observed in $22 \%$ of the patients. Of these, only $23 \%$ occurred in patients that were nonprogressors. The expression of other growth factor receptors may mediate patient response as well, either through direct stimulation of downstream pathways or through transactivation of the erbB receptors. We observed high IGF-IR expression in approximately half of the patients. IGF-IR expression alone did not correlate with patient outcome.

We found expression of erbB ligands, including NDF and TGF- $\alpha$ also varied among patients (Table 3). Approximately $70 \%$ of the patients expressed high levels of NDF while approximately $57 \%$ expressed high levels of TGF- $\alpha$. A significant correlation was observed between NDF levels and patient outcome. A very high proportion of NDF-negative patients progressed (91\%) whereas $62 \%$ of NDF-positive patients progressed compared to a $70 \%$ progression rate in the total patient group. No predictive relationship was observed between TGF- $\alpha$ levels and patient outcome (Table 3). However, the combination of TGF- $\alpha$ or NDF expression and EGFR overexpression did positively correlate with patient outcome (data not shown; $P=0.02$ and 0.03 , respectively).

The activation of heterodimers of erbB2 with erbB3 and EGFR results in activation of the ERK and PI3K/AKT pathways. Comparison of the levels of activated or phosphorylated ERK
Table 3 Receptor tyrosine kinase ligand expression vs patient outcome following therapy

\begin{tabular}{lcccc}
\hline Patient group & $\boldsymbol{n}$ & $\begin{array}{c}\% \\
\text { Nonprogressors }\end{array}$ & $\begin{array}{c}\% \\
\text { Progressors }\end{array}$ & $\begin{array}{l}\boldsymbol{\chi}^{\mathbf{2}} \text { valuel } \\
\text { P-value }\end{array}$ \\
\hline NDF positive & 55 & 39 & 62 & $6.35 / 0.02$ \\
NDF negative & 22 & 9 & 91 & \\
Total & 77 & 30 & 70 & \\
& & & & \\
TGF- $\alpha$ positive & 38 & 34 & 66 & $0.34 / \mathrm{NS}$ \\
TGF- $\alpha$ negative & 29 & 28 & 72 & \\
Total & 67 & 31 & 69 & \\
\hline
\end{tabular}

Analysis on tissue array samples for which clinical and Herceptest data were available and who overexpressed ErbB2 at the 3+ level.

Table 4 Analysis of receptor and downstream protein activation or ligand expression vs outcome in patients following therapy

\begin{tabular}{|c|c|c|c|c|}
\hline Patient group & $n$ & $\begin{array}{c}\% \\
\text { Nonprogressors }\end{array}$ & $\begin{array}{c}\% \\
\text { Progressors }\end{array}$ & $\begin{array}{l}\chi^{2} \text { valuel } \\
P \text {-value }\end{array}$ \\
\hline EGFR pos/p-ERK pos & 21 & 14 & 86 & $8.55 / 0.05$ \\
\hline EGFR pos/p-ERK neg & 19 & 42 & 58 & \\
\hline EGFR neg/p-ERK pos & 9 & 0 & 100 & \\
\hline EGFR neg/p-ERK neg & 14 & 14 & 86 & \\
\hline Total & 63 & 21 & 79 & \\
\hline EGFR pos/p-AKT pos & 17 & 18 & 82 & $6.96 / \mathrm{NS}$ \\
\hline EGFR pos/p-AKT neg & 26 & 38 & 62 & \\
\hline EGFR neg/p-AKT pos & 5 & 20 & 80 & \\
\hline EGFR neg/p-AKT neg & 18 & 6 & 94 & \\
\hline Total & 66 & 23 & 77 & \\
\hline IGF-IR pos/p-S6 pos & 13 & 8 & 92 & $10.54 / 0.02$ \\
\hline IGF-IR pos/p-S6 neg & 20 & 35 & 65 & \\
\hline IGF-IR neg/p-S6 pos & 12 & 67 & 33 & \\
\hline IGF-IR neg/p-S6 neg & 23 & 26 & 74 & \\
\hline Total & 68 & 32 & 68 & \\
\hline EGFR pos/NDF pos & 31 & 39 & 61 & $8.94 / 0.05$ \\
\hline EGFR pos/NDF neg & 12 & 8 & 92 & \\
\hline EGFR neg/NDF pos & 16 & 12 & 88 & \\
\hline EGFR neg/NDF neg & 7 & 0 & 100 & \\
\hline Total & 66 & 23 & 77 & \\
\hline
\end{tabular}

Analysis on tissue array samples for which clinical and Herceptest data were available and who overexpressed ErbB2 at the $3+$ level.

alone failed to demonstrate any significant effect of elevated p-ERK levels as a factor for patient outcome. Similarly, AKT activation (p-AKT) or phosphorylation of S6 ribosomal protein alone, which integrates multiple signals through mTOR and p70 S6 kinase, did not significantly correlate with patient outcome.

To increase the predictive power of our analysis, we next considered an analysis in which two or more of these biomarkers were combined to characterise the tumor. In this analysis we found that the combination of low EGFR expression and high ERK activation significantly predicted a poor outcome (Table 4). A comparison combining high EGFR and high p-AKT predicted a poor patient outcome as well (18 vs $38 \%$ for patients with low p-AKT levels). The combination of high EGFR and high NDF or TGF- $\alpha$ expression predicted a better outcome compared to patients that had low expression of EGFR and the ligand. For example, while $39 \%$ of the patients with high EGFR and NDF expression did not progress, all of the patients with low EGFR and NDF expression progressed (Table 4 ) compared to $23 \%$ nonprogressors in the total patient group. 
Table 5 Analysis of ligand and receptor expression and downstream protein activation vs patient outcome in patients following therapy

\begin{tabular}{|c|c|c|c|c|}
\hline Patient group & $n$ & $\begin{array}{c}\% \\
\text { Nonprogressors }\end{array}$ & $\begin{array}{c}\% \\
\text { Progressors }\end{array}$ & $\begin{array}{l}\chi^{2} \text { valuel } \\
P \text {-value }\end{array}$ \\
\hline NDF neg/p-S6 pos/IGF-IR neg & 2 & 50 & 50 & $19.41 / 0.01$ \\
\hline NDF neg/p-S6 neg/IGF-IR neg & 9 & 11 & 89 & \\
\hline NDF neg/p-S6 neg/IGF-IR pos & 4 & 0 & 100 & \\
\hline NDF neg/p-S6 pos/IGF-IR pos & 4 & 0 & 100 & \\
\hline NDF pos/p-S6 pos/IGF-IR neg & 7 & 100 & 0 & \\
\hline NDF pos/p-S6 neg/IGF-IR pos & 16 & 44 & 56 & \\
\hline NDF pos/p-S6 neg/IGF-IR neg & 14 & 36 & 64 & \\
\hline Total & 56 & 37 & 63 & \\
\hline NDF neg/p-ERK pos/EGFR neg & 3 & 0 & 100 & 12.75/NS \\
\hline NDF neg/p-ERK neg/EGFR neg & 4 & 0 & 100 & \\
\hline NDF neg/p-ERK neg/EGFR pos & 10 & 20 & 80 & \\
\hline NDF neg/p-ERK pos/EGFR pos & 6 & 0 & 100 & \\
\hline NDF pos/p-ERK pos/EGFR neg & 5 & 0 & 100 & \\
\hline NDF pos/p-ERK neg/EGFR pos & 13 & 54 & 46 & \\
\hline NDF pos/p-ERK neg/EGFR neg & 6 & 17 & 83 & \\
\hline NDF pos/p-ERK pos/EGFR pos & 18 & 28 & 72 & \\
\hline Total & 65 & 23 & 77 & \\
\hline
\end{tabular}

Analysis on tissue array samples for which clinical and Herceptest data were available and who overexpressed ErbB2 at the 3+ level.

The combination of low IGF-IR expression and high S6 ribosomal protein phosphorylation gave a favorable patient response outcome (67\% nonprogressors, Table 4$)$. This compares to patients with high IGF-IR expression and high S6 ribosomal protein phosphorylation, $8 \%$ of who were nonprogressors. The best combination of markers for the prediction of patient response was NDF, IGF-IR and p-S6 (Table 5). All of the patients who had high NDF expression, low IGF-IR expression and high S6 phosphorylation had stable disease or were disease free (however, the number of patients in this category was only seven). In comparison, all of the patients who had low NDF expression and high IGF-IR expression progressed, regardless of S6 status (Table 5). In patients with high NDF and EGFR expression levels, phosphorylation of ERK correlated with a difference in progression from 28\% (high p-ERK) to 54\% (low p-ERK; Table 5). Similarly, those patients with low levels of p-AKT with any other combination of biomarkers that includes the expression of NDF, did better than those that overexpress this protein (results not shown). Taken together, our data show that ErbB2 together with its ligand and other erbB receptors and ligands as well as other growth factor receptors play a role in Herceptin response. Importantly, analysis of a select combination of these proteins correlated with progression rates that varied from 0 to $100 \%$. Therefore, these data suggest that the use of a defined set of markers may accurately predict progression. For comparison, the 'a priori' level of prediction of progression, without the use of these biomarkers, ranged from 63 to $79 \%$

\section{DISCUSSION}

The success of Herceptin therapies in the treatment of breast cancer patients has been limited although those patients treated overexpress the ErbB2 protein. Our results demonstrate that the status of EGFR and the erbB ligands, NDF and TGF- $\alpha$ affect Herceptin therapy response in breast cancer patients. Patients whose tumors express high levels of EGFR, ErbB2 and NDF or TGF- $\alpha$ are most likely to respond. Other studies that considered cell lines in culture have shown that indeed not all tumor cells respond to inhibition of ErbB receptors, despite exhibiting aberrant EGFR and/or ErbB2 expression (Motoyama et al, 2002). In this respect, it has been reported that a combination of the EGFR-directed mAb $\mathrm{C} 225$ and the erbB2 directed mAb 4D5 or

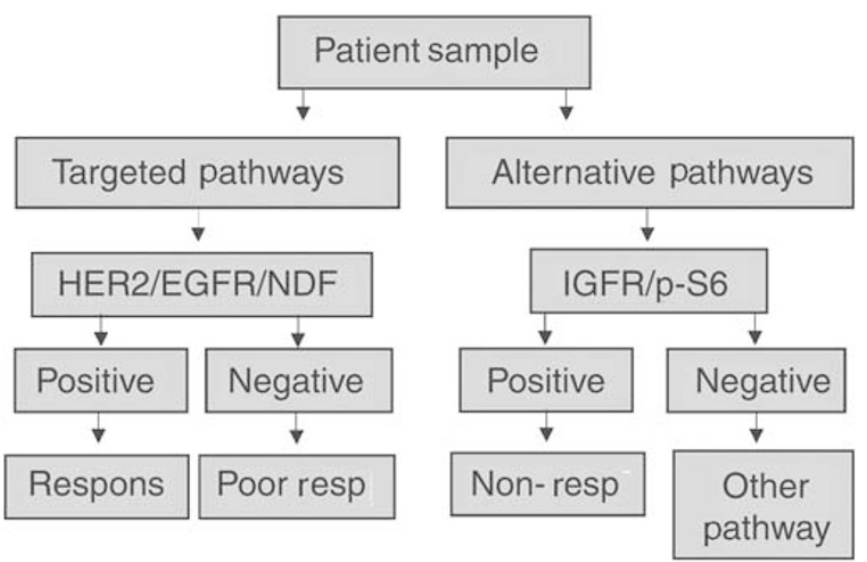

Figure 2 Diagnostic protocol for predicting patient response to combination Herceptin and chemotherapy.

using dual EGFR/HER2 inhibitors inhibited proliferation of tumor cell lines more strongly than either mAb alone (Ye et al, 1999; Motoyama et al, 2002; Xia et al, 2002). A diagnostic protocol for predicting patient response to Herceptin and chemotherapy is presented in Figure 2. The left arm of the protocol details the analysis of the targeted pathways, namely the erbB receptors and their ligands. The right arm of the protocol details the analysis of alternative pathways, namely the IGF-IR pathway and downstream signalling.

Our results suggest that the IGF-IR receptor may mediate patient response to breast cancer therapies targeting ErbB2. High IGF-IR expression combined with high S6 ribosomal protein phosphorylation correlated with poor patient response regardless of erbB expression indicating that IGF-IR was acting directly to activate downstream signalling rather than through transactivation of erbB receptors. IGF signalling in breast cancer has been shown to occur through AKT activation (Dufourny et al, 1997; Oh et al, 2002), which would lead to S6 ribosomal protein phosphorylation. Hence, S6 phosphorylation may indicate active IGF signalling in those tumors overexpressing IGF-IR. A role for IGF-IR in patient response has been suggested by cell line studies. Lu et al. (2001) reported that Herceptin resistance could occur through activation of IGF-IR. Other studies have indicated that co-targeting IGF-IR as well as ErbB2 would produce synergistic inhibition of growth in breast cancer cells (Camirand et al, 2002). Based upon our results as well as the results of these published studies, analysis of IGF-IR expression and downstream signalling may be critical for an accurate assessment of potential Herceptin response in breast cancer patients (right arm of Figure 2).

The percentage of patients that overexpress HER2 and also are positive for p-HER2 in this study is similar to the percentage observed by Thor et al, (2000). In addition, more of these patients progressed than had stable disease or were disease free following treatment. These observations clearly raise questions as to the phosphorylation status of HER2 in tumor samples. The failure to see more p-HER2 positive tumors and to see a correlation with drug response may be due to rapid dephosphorylation of the receptor in vivo or during tissue handling or inadequate sensitivity of the antibody. However, cell line studies indicate that the p-HER2 antibody is capable of detecting HER2 phosphorylation following ligand exposure (results not shown).

Our analysis of downstream signalling and patient response is complicated by the inclusion of chemo- and radiotherapy in addition to Herceptin for the patients analysed. AKT or MAP kinase pathway activation, for example, is known to play a role in response to DNA-damaging agents (Bacus et al, 2001; Clark et al, 2002). Therefore, consideration of downstream signalling 
in patients undergoing a combination of therapies may provide additional predictive information not available at the level of the receptor or ligand. Analysis of patients treated with Herceptin as a single agent therapy would be needed to determine which of the biomarkers we identified are mediating response to Herceptin itself $v s$ the other therapies. However, our results are useful in the design of diagnostic tests for breast cancer patients undergoing the common Herceptin combination therapies. The

\section{REFERENCES}

Altiok S, Batt D, Altiok N, Papautsky A, Downward J, Roberts TM, Avraham $\mathrm{H}$ (1999) Heregulin induces phosphorylation of BRCA1 through phosphatidylinositol 3-kinase/AKT in breast cancer cells. J Biol Chem 274(45): $32274-32278$

Bacus SS, Altomare DA, Lyass L, Chin DM, Farrell MP, Gurova K, Gudkov A, Testa JR (2002) AKT2 is frequently upregulated in ERBB2/neupositive breast cancers and may contribute to tumor aggressiveness by enhancing cell survival. Oncogene 21: $3532-3540$

Bacus S, Chin D, Stewart J, Zelnick C, Mahvi D, Gilchrist K (1997) Potential use of image analysis for the evaluation of cellular predicting factors for therapeutic response in breast cancers. Anal Quant Cytol Histol 19(4): $316-328$

Bacus SS, Gudkov AV, Lowe M, Lyass L, Yung Y, Komarov AP, Keyomarsi K, Yarden Y, Seger R (2001) Taxol-induced apoptosis depends on MAP kinase pathways (ERK and p38) and is independent of p53. Oncogene 20: $147-155$

Bacus SS, Ruby SG (1993) Application of image analysis to the evaluation of cellular prognostic factors in breast carcinoma. Pathol Annual 28 (Part 1): 179-204

Baselga J (2002) Combined anti-EGF receptor and anti-ERBB2 receptor therapy in breast cancer: a promising strategy ready for clinical testing. Annu Oncol 13: 8-9

Camirand A, Lu Y, Pollak M (2002) Co-targeting ERBB2/ErbB2 and insulinlike growth factor-1 receptors causes synergistic inhibition of growth in ERBB2-overexpressing breast cancer cells. Med Sci Monit Dec 8(12): BR521 - BR526

Clark AS, West K, Streicher S, Dennis PA (2002) Constitutive and inducible Akt activity promotes resistance to chemotherapy, trastuzumab, or tamoxifen in breast cancer cells. Mol Cancer Ther 1(9): 707-717

Dufourny B, Alblas J, van Teeffelen HA, van Schaik FM, van der Burg B, Steenbergh PH, Sussenbach JS (1997) Mitogenic signaling of insulin-like growth factor I in MCF-7 human breast cancer cells requires phosphatidylinositol 3-kinase and is independent of mitogen-activated protein kinase. J Biol Chem 272(49): 31163-31171

Gschwind A, Zwick E, Prenzel N, Leserer M, Ullrich A (2001) Cell communication networks: epidermal growth factor receptor transactivation as the paradigm for interreceptor signal transmission. Oncogene 20(13): $1594-1600$

Hoos A, Urist MJ, Stojadinovic A, Mastorides S, Dudas ME, Leung DH, Kuo D, Brennan MF, Lewis JJ, Cordon-Cardo C (2001) Validation of tissue microarrays for immunohistochemical profiling of cancer specimens using the example of human fibroblastic tumors. Am J Pathol 158(4): $1245-1251$

Hortobagyi GN (2001) Overview of treatment results with trastuzumab (Herceptin) in metastatic breast cancer. Semin Oncol 6(Suppl 18): 43-47 protocol outlined in Figure 2 represents a first attempt at such a diagnostic test.

\section{ACKNOWLEDGEMENTS}

We would like to thank Dr Michael DiGiovanna of Yale University for helpful discussions.
Karunagaran D, Tzahar E, Beerli RR, Chen X, Graus-Porta D, Ratzkin BJ, Seger R, Hynes NE, Yarden Y (1996) ErbB2 is a common auxiliary subunit of NDF and EGF receptors: implications for breast cancer. EMBO J 15(2): $254-264$

Liu W, Li J, Roth RA (1999) Heregulin regulation of Akt/protein kinase B in breast cancer cells. Biochem Biophys Res Comm 261: 897-903

Lu Y, Zi W, Zhao Y, Mascarenhas D, Pollak M (2001) Insulin-like growth factor-I receptor signaling and resistance to Trastuzumab (Herceptin). J Natl Cancer Inst 93(24): 1852

Motoyama AB, Hynes NE, Lane HA (2002) The efficacy of ErbB receptortargeted anticancer therapeutics is influenced by the availability of epidermal growth factor-related peptides. Cancer Res 62: 3151-3158

Oh JS, Kucab JE, Bushel PR, Martin K, Bennett L, Collins J, DiAugustine RP, Barrett JC, Afshari CA, Dunn SE (2002) Insulin-like growth factor-1 inscribes a gene expression profile for angiogenic factors and cancer progression in breast epithelial cells. Neoplasia 4(3): 204-217

Peles E, Ben-Levy R, Tzahar E, Liu N, Wen D, Yarden Y (1993) Cell-type specific interaction of Neu differentiation factor (NDF/heregulin) with Neu/ERBB2 suggests complex ligand-receptor relationships. EMBO J Mar 12(3): 961 - 971

Pinkas-Kramarski R, Shelly M, Glathe S, Ratzkin BJ, Yarden Y (1996) Neu differentiation factor/neuregulin isoforms activate distinct receptor combinations. J Biol Chem 271(32): 19029-19032

Thor AD, Liu S, Edgerton S, Moore II D, Kasowitz KM, Benz CC, Stern DF, DiGiovanna MP (2000) Activation (tyrosine phosphorylation) of ErbB-2 (HER-2/neu): a study of incidence and correlation with outcome in breast cancer. J Clin Oncol 18(18): 3230-3239

Tzahar E, Levkowitz G, Karunagaran D, Yi L, Peles E, Lavi S, Chang D, Liu N, Yayon A, Wen D, Yarden YJ (1994) Bivalence of EGF-like ligands drives the ErbB signaling network. J Biol Chem 269(40): 25226-25233

Xia W, Mullin RJ, Keith BR, Liu LH, Ma H, Rusnak DW, Owens G, Alligood KJ, Spector NL (2002) Anti-tumor activity of GW572016: a dual tyrosine kinase inhibitor blocks EGF activation of EGFR/erbB2 and downstream Erk1/2 and AKT pathways. Oncogene 21(41): 6255-6263

Xing X, Wang SC, Xia W, Zou Y, Shao R, Kwong KY, Yu Z, Zhang S, Miller S, Huang L, Hung MC (2000) The ets protein PEA3 suppresses ERBB2/neu overexpression and inhibits tumorigenesis. Nat Med 6: $189-195$

Yakes FM, Chinratanalab W, Ritter CA, King W, Seeling S, Arteaga CL (2002) Herceptin-induced inhibition of phosphatidylinositol-3 kinase and Akt is required for antibody-mediated effects on p27, cyclin D1, and antitumor action. Cancer Res 62(14): 4132-4141

Ye D, Mendelsohn J, Fan Z (1999) Augmentation of a humanized antiERBB2mAb 4D5 induced growth inhibition by a human-mouse chimeric anti-EGF receptor mAb C225. Oncogene 18(3): 731-738 